\title{
Influence of acquired obesity on coronary vessel wall late gadolinium enhancement in discordant monozygote twins
}

\author{
Marcus R. Makowski ${ }^{1,2,3,4,5}$ (D) Christian H. P. Jansen ${ }^{1} \cdot$ Ullrich Ebersberger $^{6}$ Tobias Schaeffter $^{1,2,3,4}$. \\ Reza Razavi $^{1,2,3,4}$ - Massimo Mangino ${ }^{7,8}$ - Tim D. Spector ${ }^{6}$ - Rene M. Botnar ${ }^{1,2,3,4}$. Gerald F. Greil ${ }^{1,2,3,4}$
}

Received: 9 October 2015 /Revised: 9 September 2016/Accepted: 22 September 2016/Published online: 14 October 2016

(C) The Author(s) 2016. This article is an open access publication

\begin{abstract}
Objectives The aim of this study was to investigate the impact of BMI on late gadolinium enhancement (LGE) of the coronary artery wall in identical monozygous twins discordant for BMI. Coronary LGE represents a useful parameter for the detection and quantification of atherosclerotic coronary vessel wall disease.
\end{abstract}

The original version of this article was revised:

The article was originally published electronically on the publisher's internet portal (currently SpringerLink) on 14. October 2016 without open access. As the study was partly supported by the Wellcome Trust the article has been modified. The copyright of the article changed to (c) The Author(s) [2016] and the article is forthwith distributed under the terms of the Creative Commons Attribution 4.0 International License.

Rene Botnar and Gerald Greil contributed equally to this work.

Electronic supplementary material The online version of this article (doi:10.1007/s00330-016-4616-8) contains supplementary material, which is available to authorized users.

Gerald F. Greil

gerald.greil@kcl.ac.uk

1 Division of Imaging Sciences and Biomedical Engineering, King's College London, London SE1 7EH, UK

2 Wellcome Trust and EPSRC Medical Engineering Centre, London, UK

3 BHF Centre of Excellence, King's College London, London, UK

4 NIHR Biomedical Research Centre, King's College London, London, UK

5 Department of Radiology, Charité-Universitätsmedizin, Berlin, Germany

6 Department of Cardiology and Intensive Care Medicine, Heart Center Munich-Bogenhausen, Munich, Germany

7 Department of Twin Research and Genetic Epidemiology, King's College London, London, UK

8 National Institute for Health Research (NIHR) Biomedical Research Centre at Guy's and St. Thomas' Foundation Trust, London, UK
Methods Thirteen monozygote female twin pairs $(\mathrm{n}=26)$ with significantly different BMIs $(>1.6 \mathrm{~kg} / \mathrm{m} 2)$ were recruited out of $>10,000$ twin pairs (TwinsUK Registry). A coronary 3D-T2prep-TFE MR angiogram and 3D-IR-TFE vessel wall scan were performed prior to and following the administration of $0.2 \mathrm{mmol} / \mathrm{kg}$ of Gd-DTPA on a $1.5 \mathrm{~T}$ MR scanner. The number of enhancing coronary segments and contrast to noise ratios (CNRs) of the coronary wall were quantified.

Results An increase in BMI was associated with an increased number of enhancing coronary segments $(5.3 \pm 1.5$ vs. $3.5 \pm$ $1.6, p<0.0001)$ and increased coronary wall enhancement $(6.1 \pm 1.1$ vs. $4.8 \pm 0.9, p=0.0027)$ compared to matched twins with lower BMI.

Conclusions This study in monozygous twins indicates that acquired factors predisposing to obesity, including lifestyle and environmental factors, result in increased LGE of the coronary arteries, potentially reflecting an increase in coronary atherosclerosis in this female study population.

Key points

- BMI-discordant twins allow the investigation of the influence of lifestyle factors independent from genetic confounders.

- Only thirteen obesity-discordant twins were identified underlining the strong genetic component of BMI.

- In female twins, a BMI increase is associated with increased coronary late gadolinium enhancement.

- Increased late gadolinium enhancement in the coronary vessel wall potentially reflects increased atherosclerosis.

Keywords MRI · 3D-IR-TFE · Vessel wall scan · Coronary · Twin

\section{Introduction}

Obesity has been recognized as a major contributor to the global burden of chronic disease and disability [1-3]. 
Epidemiological, clinical, and preclinical studies conducted in the field of cardiovascular medicine have led to significant progress in our understanding of modifiable and nonmodifiable risk factors in cardiovascular disease. Despite the availability of cost-effective interventions to reduce risks, the World Health Report 2002 estimated $58 \%$ of diabetes, $21 \%$ of ischemic heart disease and 8-42\% of certain cancers globally were attributable to a body mass index (BMI) above $21 \mathrm{~kg} / \mathrm{m}^{2}$. The BMI was shown to be associated with coronary atherosclerosis and the risk for cardiovascular events [4]. Although it is recognized that an increase in BMI is associated with an increase in cardiovascular events, this association is highly complex. Currently, it is not well investigated whether or to which extent this association is confounded by genetic factors [4].

Identical twins are matched for genes, age, ethnicity, gender and usually share the same lifestyle and environment [5, 6]. In addition to genetic factors, lifestyle and environmental factors can also lead to obesity, which manifests as an increase in BMI and concurrent metabolic changes. A collective of identical twins discordant for BMI offers the unique opportunity to investigate the influence of these two parameters on the development of atherosclerosis in the coronary vessel wall independent from genetic confounders.

Extravascular gadolinium-based contrast agents are paramagnetic media used in clinical routine for magnetic resonance imaging (MRI). This type of contrast agent was shown to accumulate in atherosclerotic plaques with an increased expression of fibrotic tissue components/extracellular matrix proteins, increased distribution volume, delayed clearance, or increased neovascularization [7-10]. Previous studies have demonstrated that this type of contrast agent can be used for the detection and quantification of atherosclerotic coronary vessel wall disease [8, $10,11]$. In this context, different studies have demonstrated that the extent of enhancement correlates with the severity of atherosclerosis as detected with multislice computed tomography and quantitative coronary angiography $[9,10]$.

The purpose of this study of a unique study collective of discordant monozygous twins was to investigate to which extent acquired factors predisposing to obesity, including lifestyle and environment, result in increased late gadolinium enhancement of the coronary arteries.

\section{Methods}

\section{Study population}

This project was performed in cooperation with a research group working with the TwinsUK Registry. As part of this cooperation, the TwinsUK Registry was systematically screened for subjects with significantly different BMIs. Thirteen identical twin pairs $(n=26$ subjects) with differences in BMI were recruited from more than 10,000 twin pairs from the TwinsUK Registry [12]. As a threshold, a difference in BMI between twin pairs of $1.6 \mathrm{~kg} / \mathrm{m} 2$ was chosen. The average difference in BMI between the twin pairs in this study was $6.3 \pm 4.4 \mathrm{~kg} / \mathrm{m} 2$. This small study population is due to the rarity of identical twins with significant differences in BMI (thirteen out of more than 10,000) due to the strong genetic contribution and matching lifestyles. The average difference between identical twins is usually less than one $\mathrm{kg}$. The strength of this study, however, is that monozygote twin pairs were investigated. Twins from the registry were recruited from the general population through national media campaigns in the UK. St Thomas' Hospital research ethics committee approved the study (ethics number EC95/041), and informed consent was obtained from participating twins. None of the subjects in this study had a known history of cardiovascular disease or reported symptoms relating to cardiovascular disease. Zygosity was established in all subjects by standardized questionnaire and was confirmed by DNA fingerprinting. Exclusion criteria included: twins younger than 18 years, subjects with mental disorders or unable to give consent, claustrophobia, known allergies or contraindications to gadolinium, pregnancy or breastfeeding subjects, unstable angina pectoris (CCS IV), heart failure (NYHA IV), significant cardiac arrhythmia or impaired renal function (GFR $<30 \mathrm{ml} / \mathrm{min}$ ).

\section{Risk factor assessment}

Demographics, medical history and medication were available as part of the Twins UK cohort study. Subjects were considered current smokers if they had smoked at least 1 cigarette a day within the last 30 days. Hypertension was defined as systolic blood pressure $\geq 140 \mathrm{mmHg}$, diastolic blood pressure $\geq$ $90 \mathrm{mmHg}$ or current use of antihypertensive therapy. Diabetes was defined by self-report, a haemoglobin $\mathrm{A}_{1 \mathrm{c}}$ level $\geq 6.5 \%$, or current use of hypoglycemic medication. Hypercholesterolemia was characterized by a fasting serum low-density lipoprotein cholesterol level $\geq 140 \mathrm{mg} / \mathrm{dl}$ on direct measurement or current use of lipid-lowering agents. The Framingham Risk Score (FRS) [13] was used to predict the 10-year risk of coronary heart disease in subjects without overt congenital heart disease. The BMI was calculated as body weight divided by body height squared $\left(\mathrm{kg} / \mathrm{m}^{2}\right)$. The Short Form 36 (SF-36) Health Survey questionnaire was used (see supplementary material). Intrapair differences in BMI between twin pairs were on average higher than $2.5 \mathrm{~kg} / \mathrm{m} 2$. In all twins with an increase in BMI, an increase in FRS was measured. Mean BMI was 29.6 (range 20.1-40.5) versus 35.8 (range 26.3-52.5) and mean FRS was 13.4 (range 5-18) versus 16.4 (range 10-20). For details, please see Table 1.

\section{MRI imaging and coronary vessel wall imaging}

MRI examinations were performed using a 1.5-Tesla (T) MR system (Achieva, Philips Healthcare, Best, Netherlands). The 
Table 1 Characteristics of the trial participants

\begin{tabular}{|c|c|c|c|}
\hline Characteristics & $\begin{array}{l}\text { Twin group } 1 \\
\text { Low BMI }\end{array}$ & $\begin{array}{l}\text { Twin group } 2 \\
\text { High BMI }\end{array}$ & $p$ \\
\hline \multicolumn{4}{|l|}{ Age - yrs } \\
\hline $\begin{array}{l}\text { Mean } \\
\text { Range }\end{array}$ & $\begin{array}{l}58 \\
37-70\end{array}$ & $\begin{array}{l}58 \\
37-70\end{array}$ & 1 \\
\hline Female - no. (\%) & $13(100)$ & $13(100)$ & 1 \\
\hline \multicolumn{4}{|l|}{ Body mass index } \\
\hline $\begin{array}{l}\text { Mean } \\
\text { Range }\end{array}$ & $\begin{array}{l}29.6 \\
20.1-40.5\end{array}$ & $\begin{array}{l}35.8 \\
26.3-52.5\end{array}$ & $<0.001$ \\
\hline \multicolumn{4}{|l|}{ Framingham risk score } \\
\hline $\begin{array}{l}\text { Mean } \\
\text { Range }\end{array}$ & $\begin{array}{c}13.4 \\
5-18\end{array}$ & $\begin{array}{l}16.4 \\
10-20\end{array}$ & 0.02 \\
\hline \multicolumn{4}{|l|}{ Blood pressure - $\mathrm{mm} \mathrm{Hg}$} \\
\hline $\begin{array}{l}\text { Mean } \\
\text { Range }\end{array}$ & $\begin{array}{l}137 \\
113-173\end{array}$ & $\begin{array}{l}145 \\
120-180\end{array}$ & 0.19 \\
\hline \multicolumn{4}{|l|}{ Diastolic } \\
\hline $\begin{array}{l}\text { Mean } \\
\text { Range }\end{array}$ & $\begin{array}{l}79 \\
65-98\end{array}$ & $\begin{array}{l}86 \\
67-107\end{array}$ & 0.24 \\
\hline Current Ssmoker - no. $(\%)$ & $0(0)$ & $1(8)$ & \\
\hline \multicolumn{4}{|l|}{ HDL cholesterol - mmol/1 } \\
\hline $\begin{array}{l}\text { Mean } \\
\text { Range }\end{array}$ & $\begin{array}{l}1.4 \\
0.7-2.3\end{array}$ & $\begin{array}{l}1.4 \\
0.8-1.7\end{array}$ & 0.32 \\
\hline \multicolumn{4}{|l|}{ Total cholesterol - mmol/1 } \\
\hline $\begin{array}{l}\text { Mean } \\
\text { Range }\end{array}$ & $\begin{array}{l}5.4 \\
2.8-7.3\end{array}$ & $\begin{array}{l}6.5 \\
4.7-7.6\end{array}$ & 0.01 \\
\hline
\end{tabular}

The mean and range of relevant factors are given for all twins, for the twin group with low BMI and for the twin group with high BMI. Differences between these two groups are also reported.

system was equipped with high-performance gradients with a maximum amplitude of $30 \mathrm{mT} / \mathrm{m}$ and a slew rate of $150 \mathrm{mT} / \mathrm{m} / \mathrm{msec}$. All subjects were examined in the supine position with electrocardiographic leads placed on the anterior left hemi thorax for vector ECG triggering. A 32-element cardiac phased-array receiver coil was used. All MRI examinations were performed free-breathing without the use of sedation or general anaesthesia. First, a coronary MR angiography (MRA) was performed with the previously described navigator-gated free-breathing and cardiac-triggered three-dimensional (3D) steady-state free precession sequence [14]. Imaging parameters of the coronary MRA included: a matrix of $256 \times 256$, a field of view of $320 \times 320 \mathrm{~mm}$, and the resulting acquired inplane resolution was $1.25 \times 1.25 \mathrm{~mm}$. The acquired slice thickness was $3 \mathrm{~mm}$ and the reconstructed slice thickness was $1.5 \mathrm{~mm}$. The acquisition window was limited 80 to $100 \mathrm{~ms}$. Further parameters included a repetition time/ echo time (TR/TE) of $4.2 / 2.1 \mathrm{~ms}$ and a flip angle of 110 degrees. The acquired number of slices was 24 . Based on the MRA, a coronary navigator-gated, vector ECG- triggered, fat-suppressed, T1-weighted, 3D gradient-echo inversion recovery late gadolinium enhancement sequence (Fig. 1) was planned. Image acquisition was performed in mid-diastole. To compensate for breathing, navigator gating and tracking with a 5-mm gating window was performed $[8,9,11,15]$. In all subjects, imaging using a 3D IR TFE was performed prior to and after administration of $0.2 \mathrm{mmol} / \mathrm{kg}$ of gadolinium-diethylenetriamine pentaacetic acid. Image parameters of the 3D IR TFE included: spatial resolution $1.25 \times 1.25 \times 3 \mathrm{~mm} ; 20$ slices were acquired; the repetition time was $6.1 \mathrm{~ms}$; the echo time was $1.9 \mathrm{~ms}$; and the flip angle was $30^{\circ}$. The acquisition window was limited to $80-100 \mathrm{~ms}$. The inversion time (TI) was derived from a Look-Locker sequence aiming for maximal suppression of the blood pool signal. Parallel imaging was not applied. Overall scan time was $55 \pm 3$ minutes as imaging was performed prior to and 30 to 40 minutes following the administration of gadoliniumdiethylenetriamine pentaacetic acid $[8,9,11,15]$.

\section{Data analysis}

For the analysis of the MRI data sets, the coronary artery tree was broken down into eight segments after a modified American Heart Association (AHA) classification. All segments were analysed individually (Fig. 2) [8, 16, 17]. MR images were reformatted with a semiautomatic vessel analysis tool (Soap-Bubble, release 5.0) [18]. A technique, described by Oakes at al. [19], was adapted for the quantification of coronary vessel wall enhancement with OsiriX version 3.9.1 [20]. Late gadolinium enhancement (LGE) was defined as areas in the vessel wall with a signal intensity higher than two standard deviations compared to the normal non-

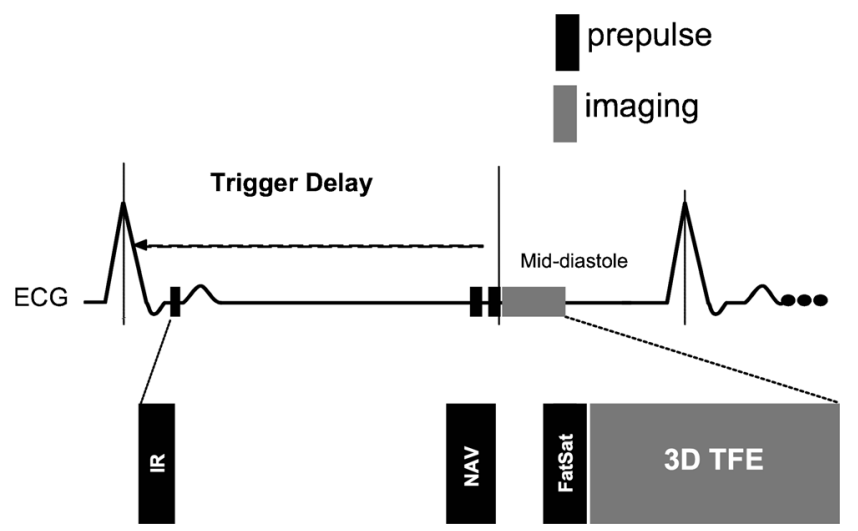

Fig. 1 MRI pulse diagram for the visualization and quantification of the contrast agent in the coronary wall. a coronary navigator-gated, vector ECG-triggered, fat-suppressed T1-weighted, three-dimensional gradientecho inversion recovery sequence (3D-IR-TFE) was performed prior to and 30 to 40 minutes after the administration of Gd-DTPA $(0.2 \mathrm{mmol} / \mathrm{kg})$. Image acquisition was performed in mid-diastole. Additionally, to compensate for breathing, navigator gating and tracking was performed 


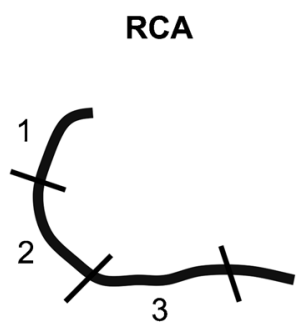

A

Fig. 2 Segmental model for the assessment of coronary enhancement. Coronary arteries were subdivided into eight segments. For an accurate identification of the segments, the segments were pre-defined according to distance from the coronary origin in the aortic root. The right coronary artery (RCA, a) was analyzed in 3 segments (1-3), the left coronary artery (LCA, b) within the left main artery ( 1 segment, 5$)$, the left anterior descending (2 segments, 6, 7), and the circumflex artery (2 segments, 11,13$)$

enhancing vessel wall. With the coronary MRA used as an overlay roadmap (automatic image fusion, Fig. 3), coronary vessel wall enhancement was measured. As the anatomy of the coronary artery tree slightly varies between twin pairs, regions of interest (ROIs) had to be adjusted manually for each twin pair. The variation of size for each segment was less than $10 \%$ between twin pairs. ROIs were exactly copied within twin pairs to enable a high reproducibility, as the anatomical tree did not show variations within twin pairs. To determine the signal intensity (SI) of blood, a contour was drawn in the ascending aorta. Noise was measured in the area anterior to the chest wall by drawing a contour manually. Contrast enhancement within the coronary wall and the aortic wall was defined as the contrast to noise ratio $\mathrm{CNR}=\left(\left(\mathrm{SI}_{\text {wall }}-\mathrm{SI}_{\text {blood }}\right) /\right.$ $\mathrm{SD}_{\text {noise }}$ ) [21]. Prior to the analysis, a trial assessment of five separate MR data sets for quality assurance was performed by the two readers together. For the analysis of the data sets, readers were blinded to the clinical information regarding the different twin groups. All data sets were analyzed independently in a blinded and random order. Late gadolinium enhancement measurements were repeated to calculate the intraobserver and interobserver variability. Two observers with $>8$ years of cardiovascular MRI experience analyzed data in an independent manner.

\section{Statistical analysis}

For statistical analysis, SPSS software (SPSS 17.0, SPS Inc., Chicago, IL, USA) was used. Results were expressed as mean \pm SD. The Shapiro-Wilk test and visual confirmation was used to confirm the normal distribution of the data. A Student's $t$ test was applied for the comparison of continuous and discrete variables. Bonferroni correction was used to correct for repeated comparisons. A $p$ value $<0.05$ was considered to indicate statistical significance.

\section{Results}

\section{Study population:}

A total of thirteen homozygote female twin pairs (median age range 37 to 70 years) were investigated. Patient and baseline characteristics of the study population are summarized in Table 1.

\section{Coronary vessel wall late enhancement}

In 101 of 104 segments (97\%), in the twin group with the lower BMI, contrast enhancement within the coronary vessel wall was assessable (Figs. 3, 4 and 5). A small number of
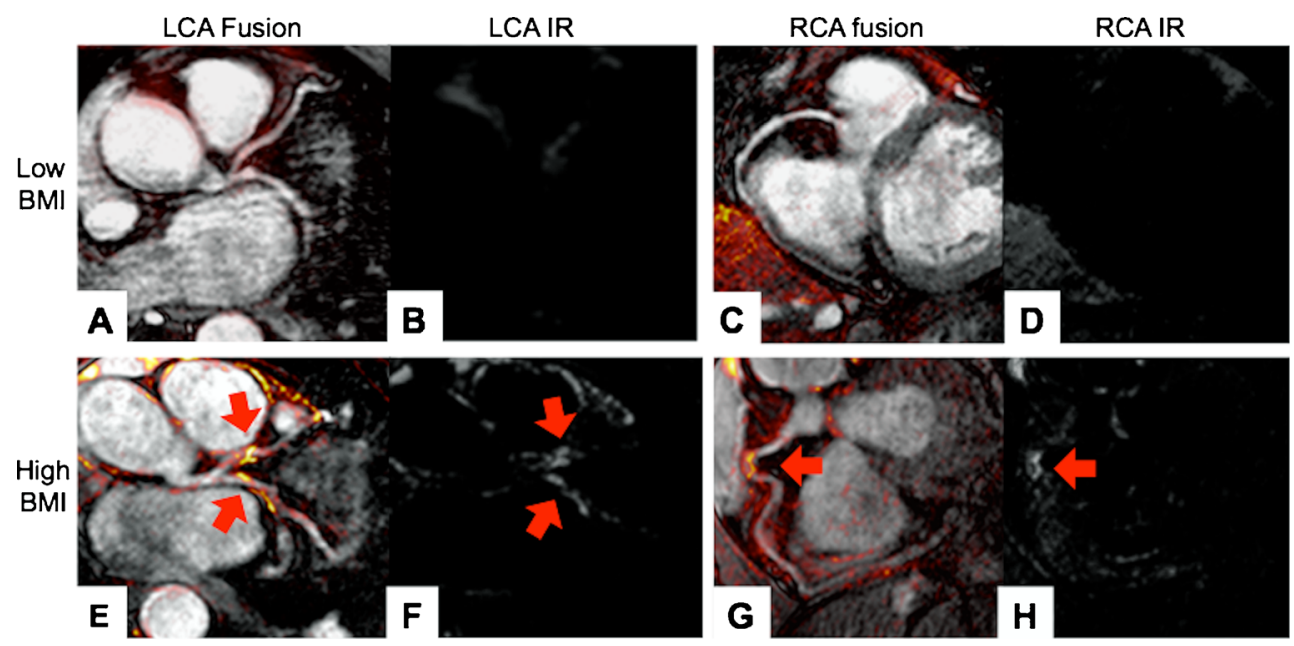

Fig. 3 Assessment of coronary enhancement after the administration of Gd-DTPA in monozygous twins. a-d: Fusion images (a, c) of coronary MRAs with matched vessel wall scans. Typical example of the enhancement pattern $(\mathbf{b}, \mathbf{d})$ in the left and right coronary artery in twins with a low BMI after administration of the Gd-DTPA. Only a mild signal

enhancement can be appreciated in the left and right coronary artery. $\mathbf{e}-\mathbf{h}$ : Example of coronary enhancement in twins with a high BMI on fused images $(\mathbf{e}, \mathbf{g})$ as well as inversion recovery images $(\mathbf{f}, \mathbf{h})$. A relatively strong coronary enhancement can be observed in the proximal right and left coronary artery (red arrow) 


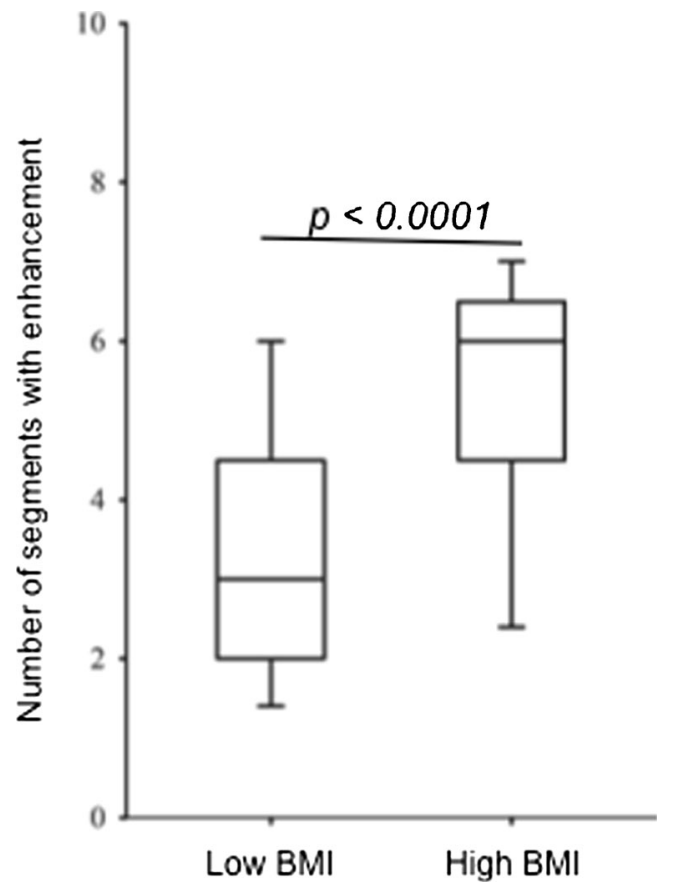

Fig. 4 Comparison of number of coronary segments with enhancement after administration of the contrast agent. The group with the high BMI showed a significantly increased number of coronary segments per subject with gadolinium enhancement compared to the twin group with the low BMI

segments had to be excluded due to motion artefacts $(n=3)$. In 99 of 104 visible segments (95\%), in the twin group with the

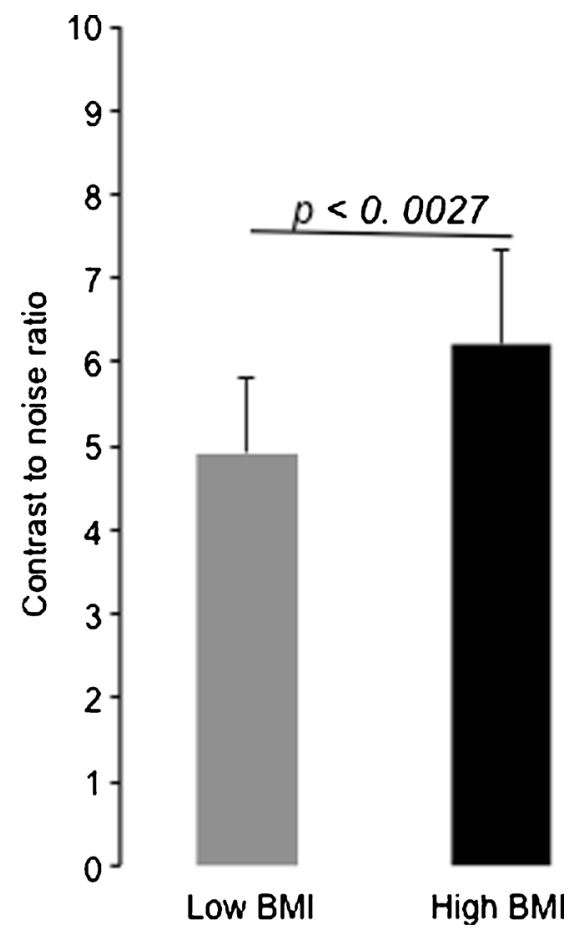

Fig. 5 Comparison of coronary contrast to noise ratios (CNRs) after administration of the contrast agent. The group with the high BMI showed a significantly increased CNR following the administration of the contrast agent compared to the twin group with the low BMI. Values are shown as mean \pm standard deviation higher BMI, contrast enhancement within the coronary vessel wall was assessable (Figs. 3, 4 and 5). A small number of segments had to be excluded due to motion artefacts $(n=5)$.

No increase in signal intensity of the coronary vessel wall was measured prior to contrast administration in all twin pairs. Following the administration of the contrast agent, the twin group with the higher BMI demonstrated an increased number of enhancing coronary segments in absolute numbers and percentage per subject $[5.3 \pm 1.5(66 \pm 19 \%)$, median $6.0,25$ th percentile $4.5,75$ th percentile

6.5] compared to the twin group with the lower BMI [ $3.5 \pm$ $1.6(44 \pm 20 \%)$, median 3.0, 25th percentile $2.0,75$ th percentile $4.5 ; p<0.0001]$. Regarding the CNR, an increase in coronary vessel wall enhancement was measured in the high BMI twin group $(6.1 \pm 1.1)$ compared to the low BMI twin group $(4.8 \pm 0.9, p<0.0027, \mathrm{n}=13$ twin pairs).

\section{Interobserver and intraobserver variability}

No significant bias was found between the two sets of repeated enhancement measurements $(\mathrm{CNR}+0.05$ for intraobserver error and +0.35 for interobserver error) measured by BlandAltman analyses. Intraobserver agreement was acceptable with $95 \%$ limits of agreement ranging from 1.1 to -1.1 . Overall, the interobserver $95 \%$ limits of agreement were 2.01 to -1.32 .

\section{Discussion}

This study in identical twins with significant differences in BMI demonstrated that an increase in BMI is associated with an increase in coronary vessel wall enhancement and the number of enhancing coronary segments. Due to the study design with monozygous twins, results are independent of genetic factors and can, therefore, be attributed to acquired factors predisposing to obesity, including lifestyle and environmental factors.

It is important to note that the study collective was limited to thirteen female identical twins with differences in BMI, which could be identified from the large TwinsUK Registry including more than 10,000 twin pairs. The fact that such a limited number of identical twin pairs could be identified, underlines the strong genetic influence on these two parameters. However, the design of our study is powerful as only monozygote twin pairs were investigated. Clear associations have been seen for other traits with these small subject numbers [22-25]. Regarding the sex of the investigated subjects, male and female subjects regularly differ in body fat distribution. It has been described that the regional distribution of body fat can be more important than excess adiposity per se in driving the risk for cardiovascular disease [26]. Therefore, the results of this investigation might not be applicable to the male population. 


\section{Association of BMI with coronary artery disease}

In this study, we could demonstrate that acquired obesity or an increase in BMI increases late gadolinium enhancement of the coronary arteries, potentially reflecting an increase in coronary atherosclerosis. From the genetical standpoint, obesity is a highly complex disorder that results in various health problems and an increase in morbidity and mortality [27]. It is recognized that complications of obesity are influenced by both, lifestyle factors and genetic predispositions. The influence of these two factors is difficult to differentiate in humans, especially in smaller patient collectives. Studies with monozygous twins discordant for obesity offer a unique opportunity to investigate the influence of these factors. Previous studies have shown that obesity is a highly heritable trait. However, environmental factors can influence the development of obesity [27]. With an increase in BMI, adipocytes start to accumulate at different sites of the body. Studies have indicated that in monozygous twins, the more obese twin demonstrates the highest increase in liver fat and intraabdominal fat, and only a moderate increase in abdominal subcutaneous fat [28]. In our study, collective with monozygote female twin pairs with significantly different BMIs, the different groups are fully matched for genes. Such twin pairs are extremely difficult to identify. Our analysis resulted in only 13 obesity-discordant twin pairs from one nationwide twin cohort. This underlines the strong genetic component of the BMI.

The effects of obesity on atherosclerosis have also been investigated. It was shown that obesity is associated with a greater risk of coronary artery calcium and an increase in carotid artery intimal medial thickness. These associations persisted after adjustment for traditional cardiovascular disease risk factors [29]. Additionally, it was shown that a strong relationship between obesity and traditional cardiovascular disease risk factors exists [29]. The association between obesity and the risk for cardiovascular diseases is mediated by different possible pathways. Obesity was shown to affect glucose levels, lipid levels and blood pressure. These factors themselves were shown to contribute to the development of atherosclerosis. On a biochemical level, obesity is thought to lead to an increase in inflammatory factors and mediators which are expressed by the increased number of adipocytes [29].

\section{Non-targeted MR contrast agents for the assessment of the coronary wall}

As the administration of non-targeted gadolinium-based contrast agents is approved for clinical use, this approach has been extensively tested in different patient collectives $[8,9,30]$. Nonspecific extracellular contrast agents, as used in this study, rapidly extravasate from the blood into the coronary vessel wall. This type of contrast agent was shown to accumulate in areas with delayed clearance, increased distribution volume or increased neovascularization [31-34]. T1 inversion recovery-based coronary vessel wall contrast-enhancement cardiovascular magnetic resonance (CE-CMR) sequences can be applied to visualize and quantify the uptake of the contrast agent into the atherosclerotic coronary wall. This approach has been validated in different patient studies and it was demonstrated that the area of coronary late enhancement correlates with the extent of coronary atherosclerosis $[8,9$, 30]._ENREF_20.

\section{Limitations:}

This study collective was based on female twin pairs. Additionally, the overall number of twin pairs was limited. This was due to the rarity of identical twins with significant differences in BMI (13 out of more than 10,000) due to the strong genetic contribution and matching lifestyles. The average difference between identical twins is usually less than one kilogram. As only female twin pairs were investigated, the application of the results to the male population may be limited. The MR assessment of coronary wall enhancement was not validated by other invasive techniques in this study, e.g. intravascular ultrasound.

In conclusion, this study in monozygous twins indicates that acquired factors predisposing to obesity, including lifestyle and environmental factors, result in increased LGE of the coronary arteries, potentially reflecting an increase in coronary atherosclerosis in this female study population.

Acknowledgments The scientific guarantor of this publication is $\mathrm{M}$. Makowski. The authors of this manuscript declare no relationships with any companies whose products or services may be related to the subject matter of the article. This study has received funding by the Department of Health through the National Institute for Health Research (NIHR) comprehensive Biomedical Research Centre award to Guy's \& St Thomas' NHS Foundation Trust in partnership with King's College London and King's College Hospital NHS Foundation Trust. The Division of Imaging Sciences receives also support as the Centre of Excellence in Medical Engineering (funded by the Wellcome Trust and EPSRC; grant number WT 088641/Z/09/Z) as well as the BHF Centre of Excellence (British Heart Foundation award RE/08/03). Further support is received from the Medical Research Council (MRC) Centre for Transplantation, King's College London, UK - MRC grant no. MR/ J006742/1 and a British Heart Foundation program and project grant (RG/12/1/29262, PG/10/044/28343). Dr. Razavi receives investigatorled research grant funding from Philips Healthcare. The study was also partly supported by the Wellcome Trust; European Community's Seventh Framework Programme (FP7/2007-2013). The magnetic resonance imaging scanner is partly supported by Philips Healthcare. Otherwise, there are no financial or other relations that could lead to a conflict of interest. No complex statistical methods were necessary for this paper. Institutional review board approval was obtained. Written informed consent was obtained from all subjects (patients) in this study. Methodology: prospective, observational, performed at one institution. 
Open Access This article is distributed under the terms of the Creative Commons Attribution 4.0 International License (http:// creativecommons.org/licenses/by/4.0/), which permits unrestricted use, distribution, and reproduction in any medium, provided you give appropriate credit to the original author(s) and the source, provide a link to the Creative Commons license, and indicate if changes were made.

\section{References}

1. Beer-Borst S, Morabia A, Hercberg S et al (2000) Obesity and other health determinants across Europe: the EURALIM project. J Epidemiol Community Health 54:424-430

2. Rosenbaum M, Leibel RL, Hirsch J (1997) Obesity. N Engl J Med 337:396-407

3. Guh DP, Zhang W, Bansback N, Amarsi Z, Birmingham CL, Anis AH (2009) The incidence of co-morbidities related to obesity and overweight: a systematic review and meta-analysis. BMC Public Health 9:88

4. Mora S, Yanek LR, Moy TF, Fallin MD, Becker LC, Becker DM (2005) Interaction of body mass index and framingham risk score in predicting incident coronary disease in families. Circulation 111: 1871-1876

5. Kendler KS, Neale MC, Kessler RC, Heath AC, Eaves LJ (1993) A test of the equal-environment assumption in twin studies of psychiatric illness. Behav Genet 23:21-27

6. Derks EM, Dolan CV, Boomsma DI (2006) A test of the equal environment assumption (EEA) in multivariate twin studies. Twin Res Hum Genet 9:403-411

7. Kim RJ, Wu E, Rafael A et al (2000) The use of contrast-enhanced magnetic resonance imaging to identify reversible myocardial dysfunction. N Engl J Med 343:1445-1453

8. Ibrahim T, Makowski MR, Jankauskas A et al (2009) Serial contrast-enhanced cardiac magnetic resonance imaging demonstrates regression of hyperenhancement within the coronary artery wall in patients after acute myocardial infarction. JACC Cardiovasc Imag 2:580-588

9. Yeon SB, Sabir A, Clouse M et al (2007) Delayed-enhancement cardiovascular magnetic resonance coronary artery wall imaging: comparison with multislice computed tomography and quantitative coronary angiography. J Am Coll Cardiol 50:441-447

10. Makowski MR, Henningsson M, Spuentrup E et al (2013) Characterization of coronary atherosclerosis by magnetic resonance imaging. Circulation 128:1244-1255

11. Maintz D, Ozgun M, Hoffmeier A et al (2006) Selective coronary artery plaque visualization and differentiation by contrast-enhanced inversion prepared MRI. Eur Heart J 27:1732-1736

12. Dunn EJ, Ariëns RA, De Lange M et al (2004) Genetics of fibrin clot structure: a twin study. Blood 103:1735-1740

13. Wilson PW, d'Agostino RB, Levy D, Belanger AM, Silbershatz H, Kannel WB (1998) Prediction of coronary heart disease using risk factor categories. Circulation 97:1837-1847

14. Spuentrup E, Buecker A, Stuber M et al (2003) Navigator-gated coronary magnetic resonance angiography using steady-state-freeprecession: comparison to standard T2-prepared gradient-echo and spiral imaging. Investig Radiol 38:263-268

15. Botnar RM, Stuber M, Kissinger KV, Kim WY, Spuentrup E, Manning WJ (2000) Noninvasive coronary vessel wall and plaque imaging with magnetic resonance imaging. Circulation 102:25822587

16. Austen WG, Edwards JE, Frye RL et al (1975) A reporting system on patients evaluated for coronary artery disease. Report of the Ad Hoc Committee for Grading of Coronary Artery Disease, Council on Cardiovascular Surgery, American Heart Association. Circulation 51:5-40

17. Kaiser C, Bremerich J, Haller S et al (2005) Limited diagnostic yield of non-invasive coronary angiography by 16 -slice multi-detector spiral computed tomography in routine patients referred for evaluation of coronary artery disease. Eur Heart J 26:1987-1992

18. Etienne A, Botnar RM, van Muiswinkel A, Boesiger P, Manning WJ, Stuber M (2002) "Soap-Bubble" visualization and quantitative analysis of 3D coronary magnetic resonance angiograms. Magn Reson Med 48:658-666

19. Oakes RS, Badger TJ, Kholmovski EG et al (2009) Detection and quantification of left atrial structural remodeling with delayedenhancement magnetic resonance imaging in patients with atrial fibrillation. Circulation 119:1758-1767

20. Hussain T, Fenton M, Peel SA et al (2013) Detection and grading of coronary allograft vasculopathy in children with contrast-enhanced magnetic resonance imaging of the coronary vessel wall. Circ Cardiovasc Imag 6:91-98

21. Desai MY, Stone JH, Foo TK, Hellmann DB, Lima JA, Bluemke DA (2005) Delayed contrast-enhanced MRI of the aortic wall in Takayasu's arteritis: initial experience. Am J Roentgenol 184:14271431

22. Hopper JL, Seeman E (1994) The bone density of female twins discordant for tobacco use. N Engl J Med 330:387-392

23. Graner M, Seppala-Lindroos A, Rissanen A et al (2012) Epicardial fat, cardiac dimensions, and low-grade inflammation in young adult monozygotic twins discordant for obesity. Am J Cardiol 109:1295-1302

24. Hannukainen JC, Borra R, Linderborg K et al (2011) Liver and pancreatic fat content and metabolism in healthy monozygotic twins with discordant physical activity. J Hepatol 54:545-552

25. Noga JT, Vladar K, Torrey EF (2001) A volumetric magnetic resonance imaging study of monozygotic twins discordant for bipolar disorder. Psychiatry Res 106:25-34

26. Despres JP (2012) Body fat distribution and risk of cardiovascular disease: an update. Circulation 126:1301-1313

27. Naukkarinen J, Rissanen A, Kaprio J, Pietilainen KH (2012) Causes and consequences of obesity: the contribution of recent twin studies. Int J Obes (Lond) 36:1017-1024

28. Pietilainen KH, Rissanen A, Kaprio J et al (2005) Acquired obesity is associated with increased liver fat, intra-abdominal fat, and insulin resistance in young adult monozygotic twins. Am J Physiol Endocrinol Metab 288:E768-E774

29. Burke GL, Bertoni AG, Shea S et al (2008) The impact of obesity on cardiovascular disease risk factors and subclinical vascular disease: the Multi-Ethnic Study of Atherosclerosis. Arch Intern Med 168:928-935

30. Kim WY, Stuber M, Bornert P, Kissinger KV, Manning WJ, Botnar RM (2002) Three-dimensional black-blood cardiac magnetic resonance coronary vessel wall imaging detects positive arterial remodeling in patients with nonsignificant coronary artery disease. Circulation 106:296-299

31. Cai J, Hatsukami TS, Ferguson MS et al (2005) In vivo quantitative measurement of intact fibrous cap and lipid-rich necrotic core size in atherosclerotic carotid plaque: comparison of high-resolution, contrast-enhanced magnetic resonance imaging and histology. Circulation 112:3437-3444

32. Langerak SE, Kunz P, Vliegen HW et al (2001) Improved MR flow mapping in coronary artery bypass grafts during adenosine-induced stress. Radiology 218:540-547

33. Yuan C, Kerwin WS, Ferguson MS et al (2002) Contrast-enhanced high resolution MRI for atherosclerotic carotid artery tissue characterization. J Magn Reson Imaging 15:62-67

34. Norenberg D, Ebersberger HU, Diederichs G, Hamm B, Botnar RM, Makowski MR (2015) Molecular magnetic resonance imaging of atherosclerotic vessel wall disease. Eur Radiol. doi:10.1007 /s00330-015-3881-2 